\title{
The Influence of Damping on Vibration Induced by High-Speed Trains
}

\author{
Z. Dimitrovová and J.N. Varandas \\ UNIC, Department of Civil Engineering \\ New University of Lisbon, Monte de Caparica, Portugal
}

in B.H.V. Topping, (Editor), "Proceedings of the Eleventh International

Conference on Civil, Structural and Environmental Engineering Computing",

Civil-Comp Press, Stirlingshire, UK, Paper 47, 2007. doi: 10.4203/ccp.86.47

\begin{abstract}
Passage of high-speed trains may induce high ground and track vibrations, which, besides increasing wheel, rail and track deterioration, may have a negative impact on the vehicle stability and on the passengers comfort. In this paper two distinct analyses are presented. The first one is dedicated to efficient decoupling of rail and soil vibrations by suggesting new interface materials in rail-sleeper fixing system, i.e. in the part where damping efficiency can be directly controlled and tested. The second analysis concerns with an adequate model of soils damping. Proper understanding and correct numerical simulation of this behaviour can help in suggesting soil improvement techniques.
\end{abstract}

Keywords: high-speed trains, induced vibration, finite element modelling, commercial software, decoupling of vibrations, negative stiffness, composite materials, Reuss bound, Rayleigh damping, numerical analysis.

\section{Introduction}

Passage of high-speed trains (HST) may cause environmental problems, as they induce high ground and track vibrations, which, besides increasing wheel, rail and track deterioration, propagate through the soil, interact with nearby buildings and cause discomfort of the habitants. In addition, these vibrations have a negative impact on the vehicle stability and on the passengers comfort. As the train velocity increases, noise and soil vibrations are getting more important, especially when trains reach the critical speed corresponding to the natural wave velocity of the ground-track system. In such case, excessive ground vibrations are generated causing damages not only in the track assemblage, but fatigue failure of the rails can occur and disruption of the power supply to the trains is possible [1]. These facts are well known in the railway community since 1997. The rapid extension of the high speed rail network throughout Europe has initiated a lot of research on prediction 
models for train induced vibrations. In order to improve design and safety, specific analyses leading to realistic estimates of vibration amplitudes are required. Full understanding of these phenomena will assist to the development of new construction solutions and mitigation of undesirable features.

Detailed information on surrounding soil vibrations can only be gathered from full three-dimensional (3D) models. Finite element (FE) analyses are able to predict many kinds of ground vibrations. However, close to the train critical speed, very fine meshes are required to capture accurately the generated waves, involving computing times impractical for ordinary design. For this reason, simplified two-dimensional (2D) models are often used. As a numerical analysis involving all construction details is quite complex, commercial software is usually adopted for this purpose. ABAQUS, ANSYS and LS-DYNA programs were already used by other researchers, but there is still lack of unified approaches and clearly stated reliable analyses.

Hybrid methods, implemented in the computer code VibTrain, can significantly reduce the computational time. Good agreement with monitored results was obtained [1]. These achievements make part of the SUPERTRACK project [http://www.supertrack.no].

Experimental data related to the passage of high-speed trains are already available, but remain scarce. They are inevitable in order to validate numerical calculations.

In order to perform an accurate numerical analysis, the model size and the boundary conditions must be dealt with carefully. Another important factor is the representation of dynamic loads applied to the rail. Particular attention must also be put on the specification of material properties, especially damping, as the adoption of inappropriate damping coefficients can drastically distort the output. Since the damping ratio can generally be predicted with reasonable confidence, implementation in the numerical model of Rayleigh damping is usually based on an estimate of this ratio. This procedure requires evaluation of damping constants $\alpha$ and $\beta$, which may not be a simple task. Alternatively, commercial software packages offer different possibilities for damping introduction and variation over the model or over the analysis. Although, in the numerical modelling, usually frequency dependent Rayleigh damping is implemented, experience shows that energy dissipated by internal friction in a real system does not depend on frequency. Ideally complex shear and bulk moduli should be used, but this approach is rarely available in commercial software. In ANSYS it is possible to implement complex moduli only in harmonic analysis, which is not suitable for our case. In [3], nonlinear time domain site response analysis is used to capture the soil hysteretic response and nonlinearity due to medium and large ground motions. Soil damping is captured primarily through the hysteretic energy dissipating response. The extended Rayleigh damping formulation is introduced to reduce the overdamping at high frequencies.

There are basically two levels of damping, one is inherent to the interface material implemented in the rail-sleeper fixing system, the other one is a consequence of hysteretic soil properties and must be modelled correctly to obtain reliable results. Full understanding and correct modelling of the latter feature is inevitable for soils improvement treatment suggestion. Interface damping can be 
controlled directly, and might be improved by introduction of new and more efficient materials. In this context continuous damping is obviously more efficient than the discrete one, but traditionally in south and western Europe, sleeper-based designs, permitting only discrete damping are implemented. A novel approach, which uses embedded rails, was developed in The Netherlands. This solution permits a very efficient continuous damping, allowing a significant increase of the critical train speeds on soft soils. The elastomeric materials that have to be used in this configuration are the main source of the cost. Therefore, optimization tools are applied in the design [3].

Although, slab-track solutions may offer certain advantages to the traditional ballasted tracks, in Portugal only ballasted lines are present and therefore this study is solely concerned with them. In this paper, full 3D model for a case study is constructed in a parametric way. Analyses performed by ANSYS and LS-DYNA are compared, [4]. Viability of 2D models is discussed, either as a longitudinal cut or as a transversal cut of the thee-dimensional model. For this purpose, full transient analyses are performed. Two types of damping, specified above, are examined. New materials are suggested in order to decouple efficiently rail and soil vibrations. Implementation of Rayleigh damping of soils is commented. Capabilities and limitations of numerical simulations are highlighted. In conclusion, this work contributes to a better understanding of surrounding soil vibrations, permitting better control of the train velocity and optimization of track design. Some developments make part of research project "Response of system railway track-soil to loads imposed by high speed trains" POCI/ECM/61114/2004, founded by Portuguese supporting research entity (Fundação para a Ciência e a Tecnologia).

The paper is organized as follows. In Section 2 a case study is described and 3D FE model is presented together with discussion of viability of the results obtained by simplified analysis in longitudinal and transversal cuts. Then in Section 3 analysis in longitudinal cut is presented in order to optimize interface damping and to suggest new materials. Negative stiffness materials and composite materials saturating lower Reuss bound in dynamic correspondence principle of the theory of linear viscoelasticity are mentioned in this context. Further, in Section 4 analysis in transversal cut is presented and possibility of Rayleigh damping implementation is discussed. Conclusions are summarized in Section 5.

\section{Case study}

As a case study, model of HST rail track, described in [5-6], between Brussels and Paris is used. The track corresponds to a classical ballasted solution. UIC 60 rail with standard properties is fixed by Pandroll E2039 rail fixing system of rigidity $100 \mathrm{MN} / \mathrm{m}$ and thickness $0.01 \mathrm{~m}$ of the rail pads to the prestressed concrete monoblock sleepers. Other properties of the track model are summarized in Table 1.

Parametric file, exploiting ANSYS parametric design language (APDL), serving for geometry, material models and FE mesh generation was developed. Model with 11 sleepers was chosen due to software and computer limitations for preliminary analysis. Advantage is taken of symmetry. Rail is modelled by beam elements, interface material by discrete spring-damper elements and in the rest of the model 
linear brick elements with 8 nodes are implemented. FE mesh is visualized in Figures 1 and 2. For the sake of simplicity, linear elastic properties of all constituents were implemented, no damping characteristics were specified and the load was simulated by unit constant moving force. Test velocity was selected as $314 \mathrm{~km} / \mathrm{h}$.

\begin{tabular}{|c|c|c|c|c|}
\hline $\begin{array}{c}\text { Property/ } \\
\text { Constituent }\end{array}$ & $\begin{array}{c}\text { Dimensions } \\
{[\mathrm{m}]}\end{array}$ & $\begin{array}{c}\text { Density } \\
{\left[\mathrm{kg} / \mathrm{m}^{3}\right]}\end{array}$ & $\begin{array}{c}\text { Young's } \\
\text { modulus [MPa }]\end{array}$ & $\begin{array}{c}\text { Poisson's } \\
\text { ratio }\end{array}$ \\
\hline Sleeper & $2.5 \times 0.285 \times 0.205$ & 2054 & 30000 & 0.2 \\
\hline Ballast 25/50 & 0.3 & 1800 & 200 & 0.1 \\
\hline Sub-ballast 0/32 & 0.2 & 2200 & 300 & 0.2 \\
\hline $\begin{array}{c}\text { Limestone } \\
\text { supporting layer } \\
\text { 0/80-0/120 }\end{array}$ & 0.5 & 2200 & 400 & 0.2 \\
\hline Substrate 1 & 1.5 & 1850 & 48.1 & 0.3 \\
\hline Substrate 2 & 2.4 & 1850 & 85.1 & 0.3 \\
\hline Substrate 3 & $\infty$ & 1850 & 245.7 & 0.3 \\
\hline
\end{tabular}

Table 1: Dimensions and material properties and of the case study model.

Confirmation of suggested Poison's ratio and calculation of Young's modulus was done according to well-known relations:

$$
\mathrm{v}_{\mathrm{s}}=\sqrt{\frac{\mathrm{G}}{\rho}}=\sqrt{\frac{\mathrm{E}}{2 \rho(1+v)}} \text { and } \frac{\mathrm{v}_{\mathrm{p}}}{\mathrm{v}_{\mathrm{s}}}=\sqrt{\frac{2-2 v}{1-2 v}} \text {, }
$$

where $v_{s}, v_{p}, G, E, \rho$ and $v$ correspond to shear and pressure wave velocity propagation, shear and Young's modulus, density and Poisson's ratio. According to [5], velocities were measured as $\mathrm{v}_{\mathrm{s}}=100,133,226 \mathrm{~m} / \mathrm{s}$ and $\mathrm{v}_{\mathrm{p}}=187,249,423 \mathrm{~m} / \mathrm{s}$ for substrates 1 to 3 , respectively.

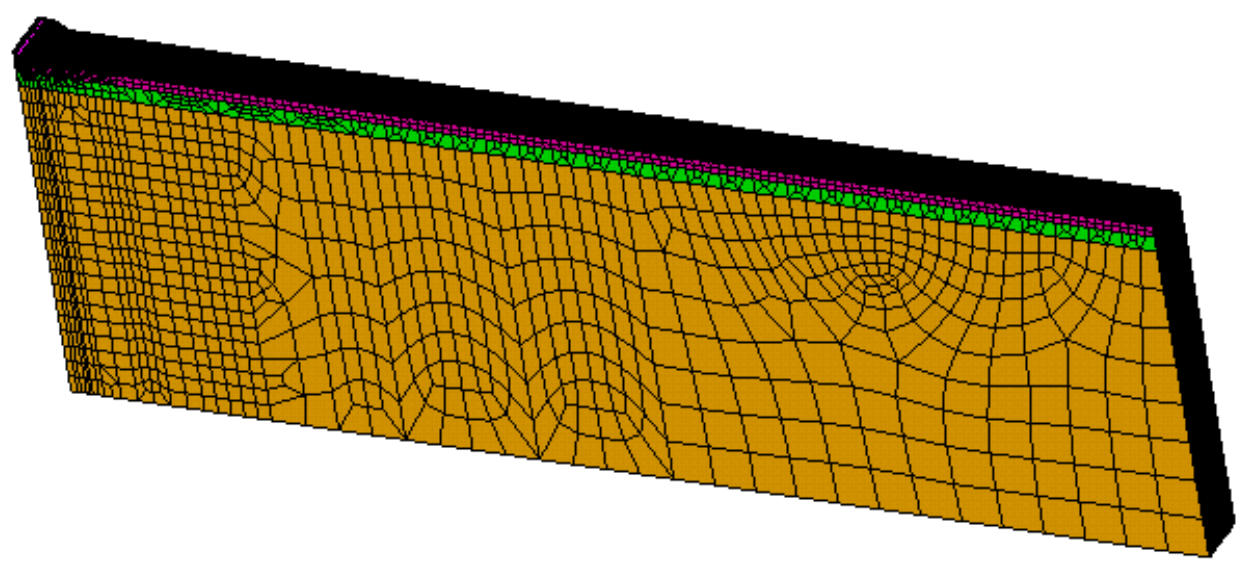

Figure 1: 3D FE model simplified by symmetry. 
Choice of linear elastic behaviour with no damping introduction is also justified by the fact, that in huge amount of results, which is available in $3 \mathrm{D}$ analysis, it might be difficult to see the influence of separate parameters. In order to avoid initial transient effects, the load was imposed on the rail above the middle point of the $3^{\text {rd }}$ sleeper and let actuate during 20s. Then it moved according to the selected speed, $314 \mathrm{~km} / \mathrm{h}$. In 30 time steps it reached the middle of the $8^{\text {th }}$ sleeper, passing in total $3 \mathrm{~m}$. Computation last over 1 day. In Figure 1 the model looks quite large in transversal direction, but non-reflecting boundary conditions are not available in the code. Therefore normal displacements were restrained on the "infinite" boundaries. The model size is in accordance with conclusions of a previous analysis, done on 2D transversal cut model under plane strain conditions. In this analysis, summarized in an internal report, surface acceleration was compared to experimental results. Total of 14 accelerometer positions were specified according to [6], the last one was displaced from the middle axis model by $72 \mathrm{~m}$. It was concluded that the adequate thickness of the last substrate is $40 \mathrm{~m}$, giving total deepness of foundation soils $43.3 \mathrm{~m}$; and the adequate extension of the model beyond the last accelerometer is $64 \mathrm{~m}$, giving total length of $136 \mathrm{~m}$ from the middle axes model.

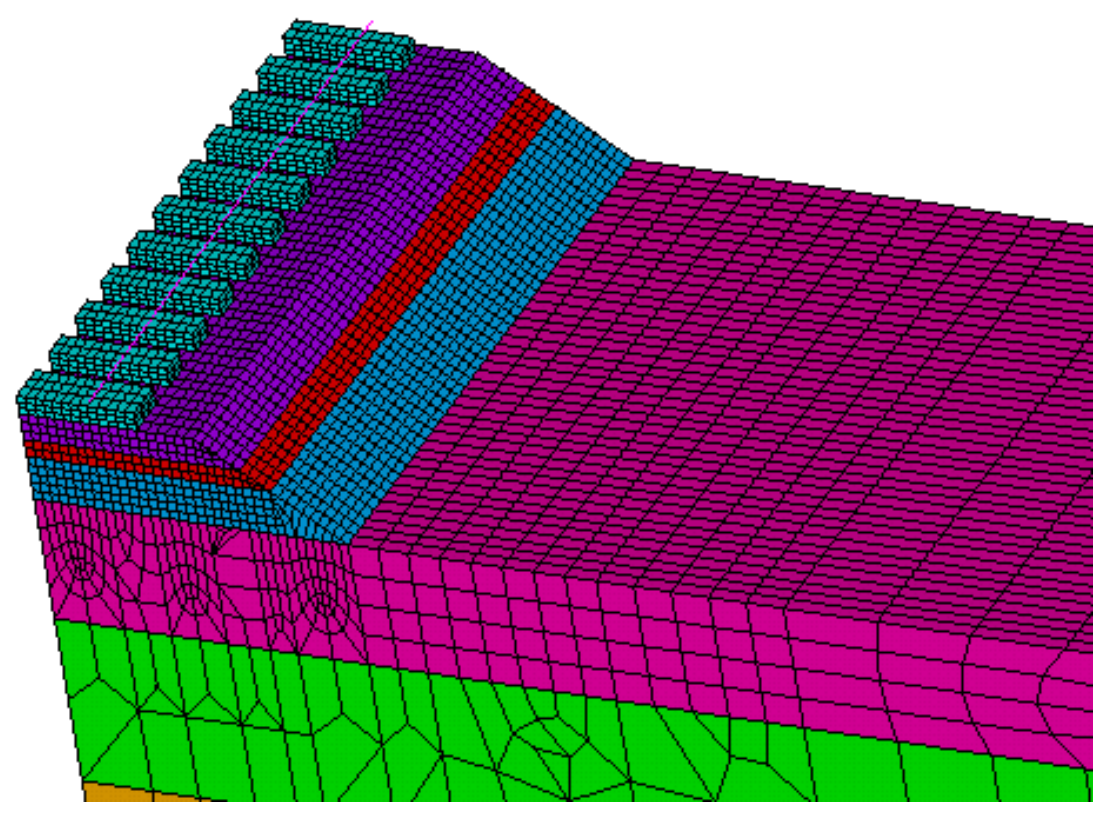

Figure 2: Detail of 3D FE model simplified by symmetry.

Parametric file can be used in ANSYS as well as in LS-DYNA software, therefore results obtained by ANSYS and LS-DYNA were compared first. LSDYNA software allows introduction of non-reflecting boundary conditions, permitting significant reduction of the model size. In the preliminary analysis large ANSYS model (Figure 1), reduced ANSYS model and reduced LS-DYNA model were compared. Results coincidence was not satisfactory, therefore further analyses were performed on ANSYS software only. In this context it can be mentioned, that in [7], sleepers were modelled as rigid bodies. 
The objective of the preliminary results is to validate usage of the analyses in the longitudinal and transversal cuts. Then longitudinal cut model will be used for fixing system damping optimization and transversal cut for correct model of hysteretic soil damping, affecting lateral waves propagation. With this purpose, elastic forces in discrete springs and surface displacements and accelerations in the middle cut of the model were extracted. Results are presented in corresponding parts of the $2 \mathrm{D}$ models.

\subsection{Model for longitudinal cut analysis}

The objective of the analysis in longitudinal cut is to study and optimize efficiency of interface pad damping, which is the model part that can be directly controlled and improved by suggesting new materials. For the interface analysis it is not necessary to make the FE model so deep as for the waves propagation, because damping efficiency can be verified directly bellow the sleepers. Model generation is again accessed by parametric file, with only ballast and sub-ballast layers included. In preliminary comparison, 2D model must copy 3D model assumptions, therefore no granular material model is implemented and sleepers slip is omitted. Nevertheless, variable embedding of sleepers is introduced, as it is more realistic (see Figure 3). Detail of FE mesh is shown in Figure 4. Spring elastic forces are compared in Figures 5-6. Here the results coincidence from 3D and 2D approach is obviously excellent, but other results also resemble same features. It must also be pointed out, that graphs in Figures 5-6 resemble features of quasi-static analysis, which validate dimensions and properties of the models. This justifies further utilization of the 2D longitudinal approach.

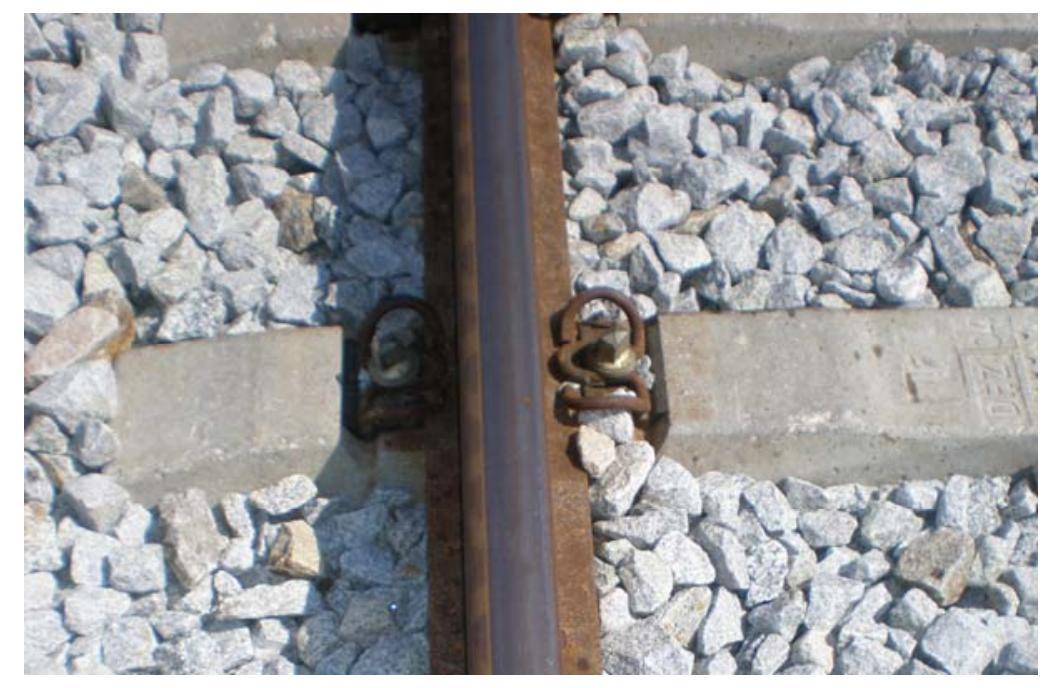

Figure 3: Photograph of traditional ballasted track showing detail of fixing system and embedding of sleepers.

It was verified that the sum of elastic forces in each time step corresponds to the applied load and that the directly loaded sleeper supports $40 \%$ of the load. In 
addition, in Figure 7, elastic force distribution is plotted over time. It is seen, that it resembles soil reaction of beam on elastic foundation, studied in [8]. In order to define an evolution loading curve, which is necessary to simulate moving load in $2 \mathrm{D}$ analysis in transversal cut, analytical solution of beam on elastic foundation subjected to moving load was examined. As decisive parameters maximum peak and curve opening in time were considered. Following [8], same curve opening can be obtained if the beam, corresponding to the rail, is posed on elastic layer with $100 \mathrm{MN} / \mathrm{m}^{2}$ Winkler constant. However, then the maximum peak must be reduced. Comparison of analytical estimate with numerical solution is presented in Figure 7.

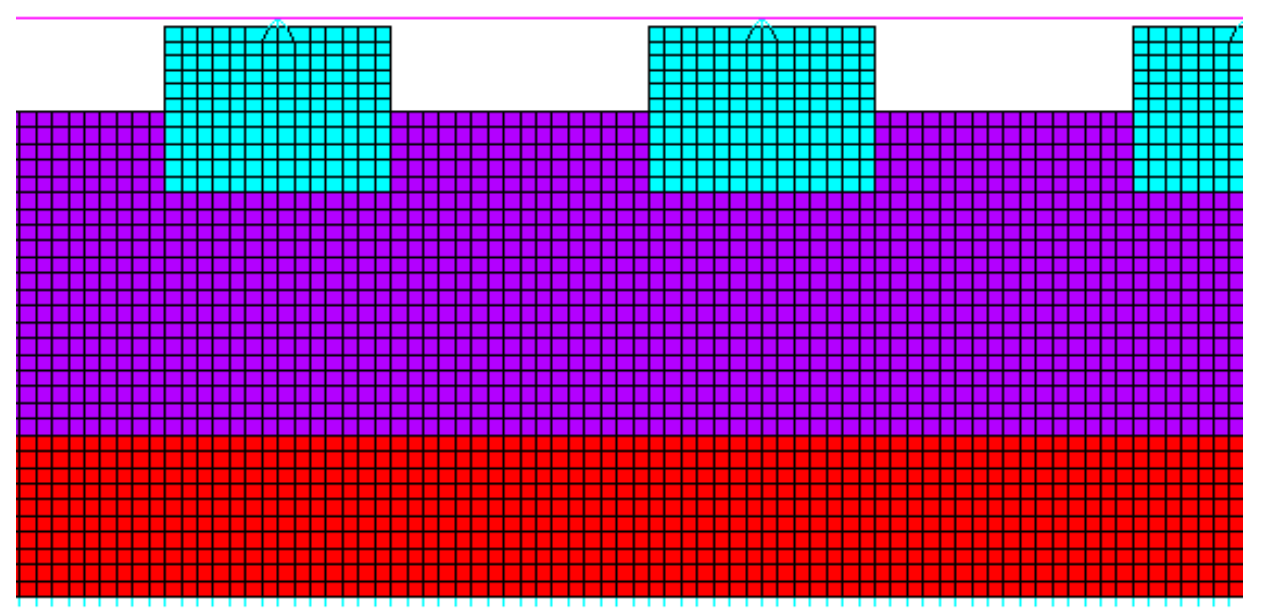

Figure 4: Detail of 2D FE model for analysis in longitudinal cut.

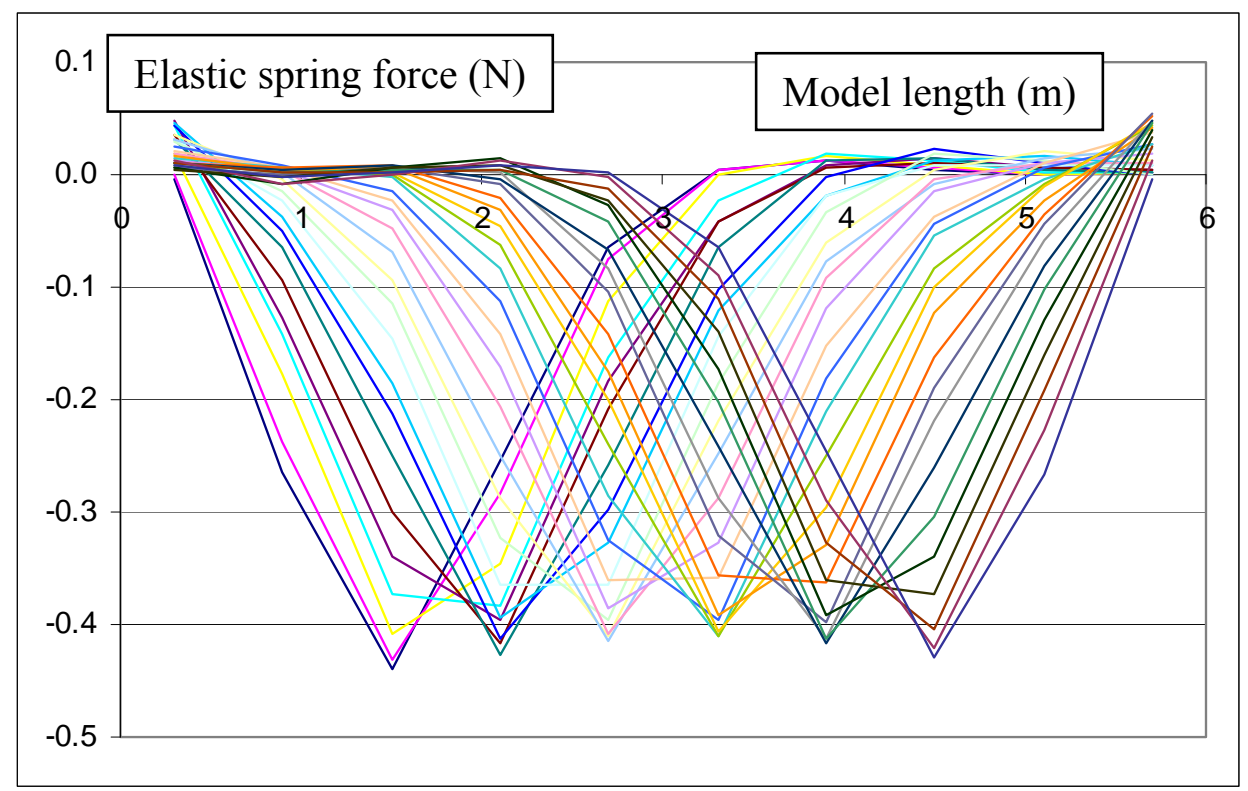

Figure 5: Elastic spring forces from 3D analysis along model length. 


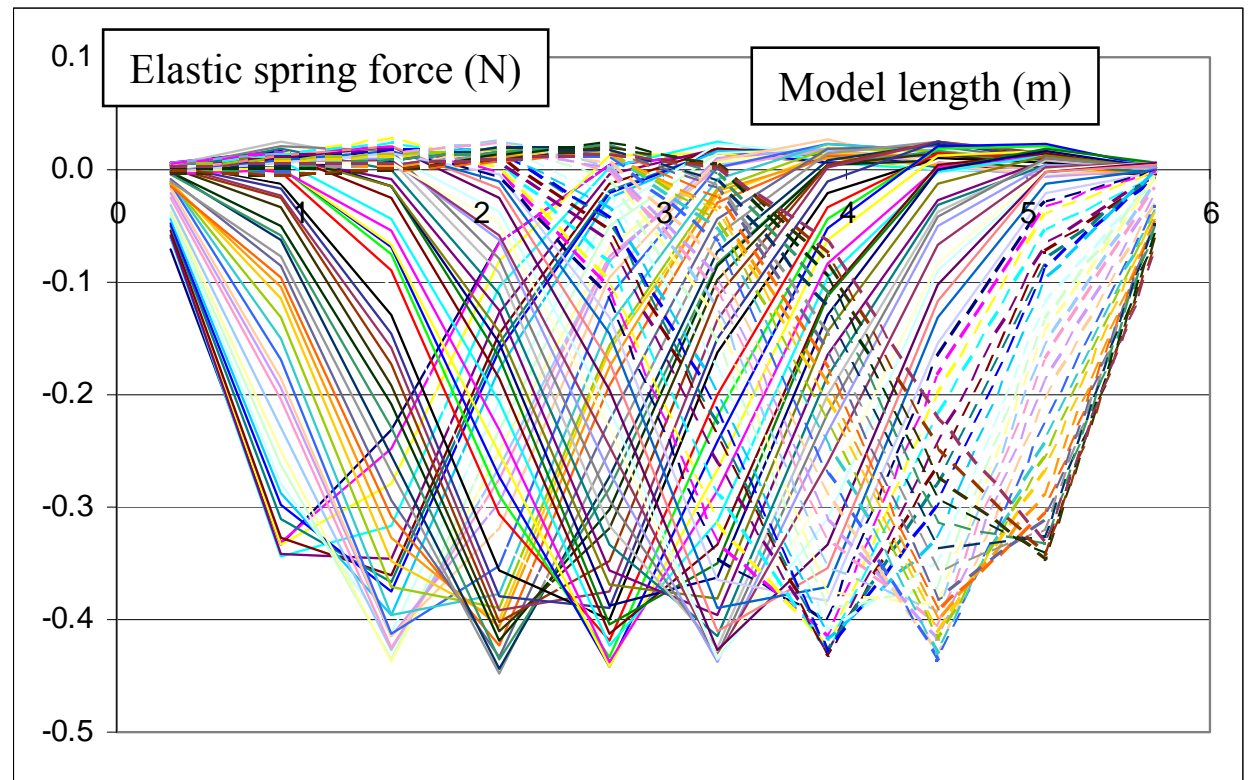

Figure 6: Elastic spring forces from 2D analysis in longitudinal cut along model length.

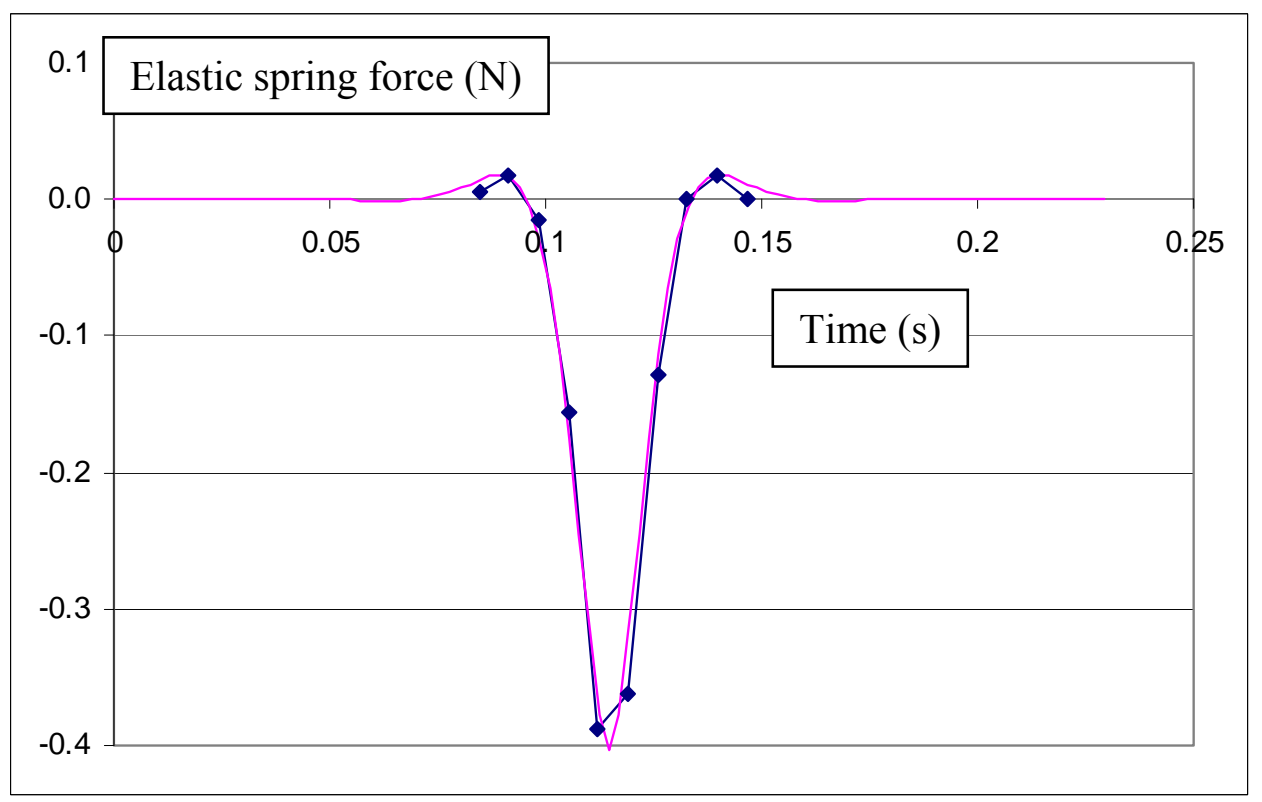

Figure 7: Elastic spring force evolution over time (violet curve: analytical estimate; blue curve: numerical results).

\subsection{Model for transversal cut analysis}

The objective of the FE analysis in transversal cut is to study adequacy of soil damping modelling. Besides the model characterization specified in previous 
sections, it is necessary to substitute the discrete sleepers by a continuous adequate material. Therefore sleeper height was switched from $h=0.205 \mathrm{~m}$ to $\mathrm{h}_{\mathrm{e}}=0.160 \mathrm{~m}$ and density from $\rho=2054 \mathrm{~kg} / \mathrm{m}^{3}$ to $\rho_{\mathrm{e}}=1250 \mathrm{~kg} / \mathrm{m}^{3}$, in order to keep moment of inertia and total sleepers mass. Simple calculation is shown in Equations (1-2):

$$
\begin{gathered}
\frac{\frac{1}{12} \mathrm{bh}^{3}}{\mathrm{~d}}=\frac{\frac{1}{12} 0,285 \cdot 0,205^{3}}{0,6}=\frac{1}{12} \mathrm{~h}_{\mathrm{e}}^{3} \Rightarrow \mathrm{h}_{\mathrm{e}}=0,160 \mathrm{~m}, \\
\frac{\mathrm{bh} \rho}{\mathrm{d}}=\frac{0,285 \cdot 0,205 \cdot 2054}{0,6}=\mathrm{h}_{\mathrm{e}} \cdot \rho_{\mathrm{e}}=0,160 \rho_{\mathrm{e}} \Rightarrow \rho_{\mathrm{e}}=1250 \mathrm{~kg} / \mathrm{m}^{3} .
\end{gathered}
$$

Here $b=0,285 \mathrm{~m}$ and $\mathrm{d}=0,6 \mathrm{~m}$ stand for sleeper depth and central line spacing in longitudinal direction.

Except for the sleepers, the 2D model was constructed using the same rules for geometry, material properties, main dimensions and element size as the 3D model. Load was imposed according to loading curve, as described in previous section, directly on modified sleeper. Results are summarized in Figures 8-9. In this seen, that surface acceleration suffers both, quantitative as well as qualitative discrepancy. Qualitative discrepancy disappears on surface in locations distant from the symmetry axis and inside the soil region sufficiently distant from the surface. Nevertheless, quantitative discrepancy maintains overall the model. In conclusion, analysis in transversal cut can be used only for soils damping modelling qualitative comparison.

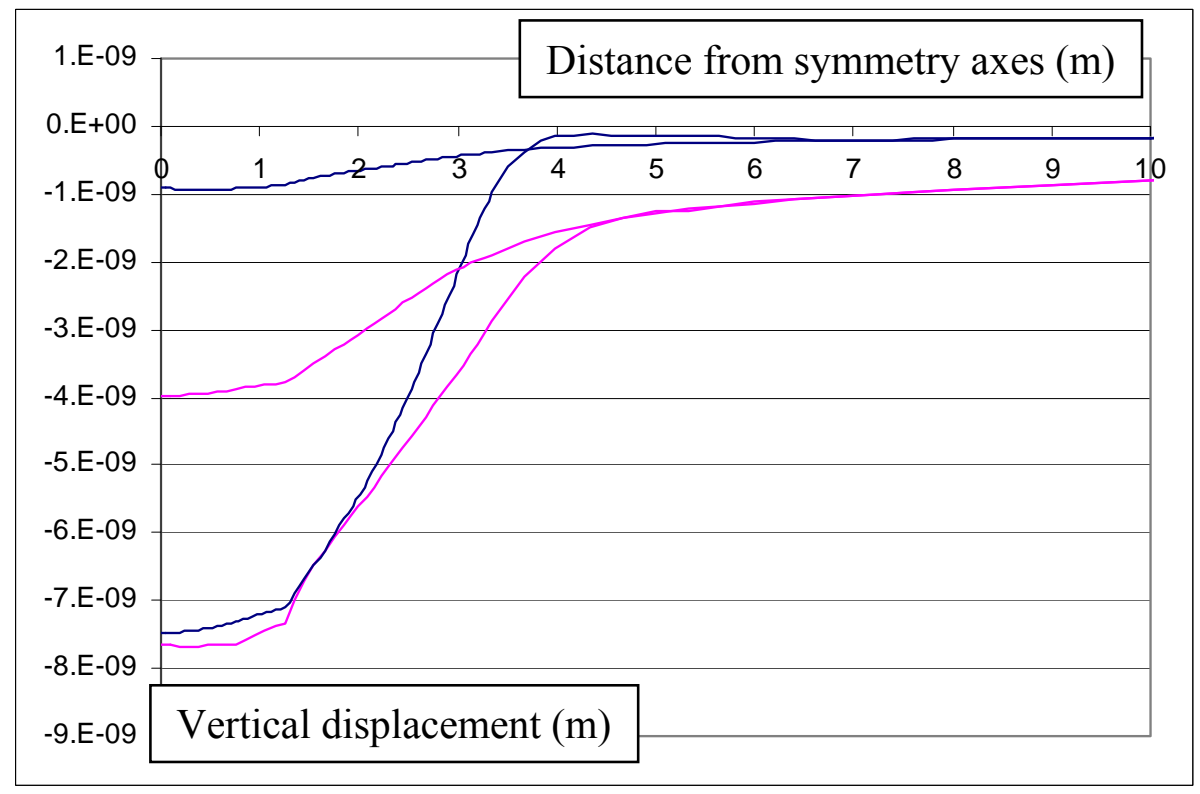

Figure 8: Initial and final vertical surface displacement distribution in central region (violet curve: 3D model; blue curve: 2D model). 


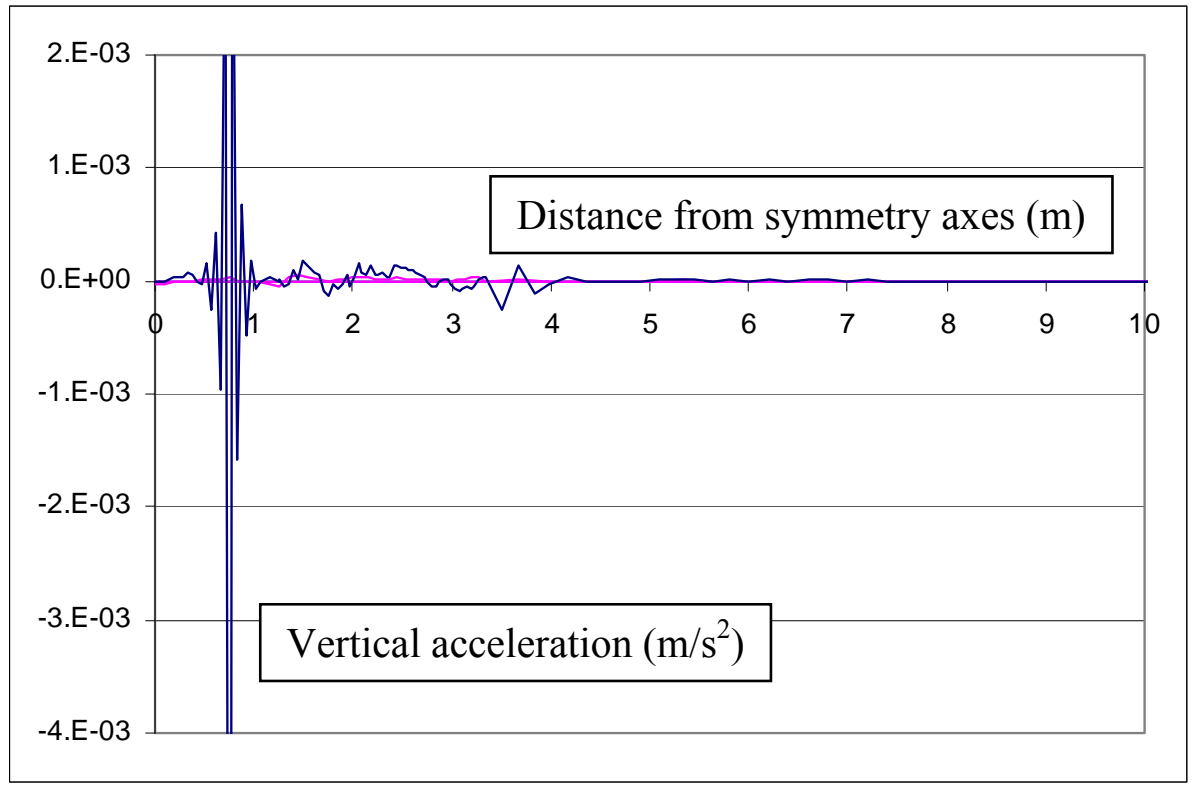

Figure 9: Initial and final vertical surface acceleration distribution in central region (violet curve: 3D model; blue curve: 2D model).

\section{Analysis in longitudinal cut}

As already mentioned, analysis in transversal cut will be used for optimization of the rail pad damping properties, in order to decouple, in the most efficient way, rail and soil vibrations. This might involve new materials selection. It is known, that vibration protecting devices have common disadvantage: they cannot ensure high stiffness together with high damping, meaning that in natural materials, when one of this property is increasing, the other one is decreasing. Materials that combine high damping and high stiffness are not common. In this paper optimal composites ensuring not only high stiffness but also high damping are examined.

\subsection{Vibration protecting systems with negative or quasi-zero stiffness}

Devices with quasi-zero or negative stiffness are promising solution to achieve simultaneously high stiffness as well as high damping. As negative stiffness components are not stable, they can be embedded in viscoelastic matrix, forming composites, which offer even better properties [9-10]. In these systems, any desired stiffness may be ensured at a given load bearing capacity.

The basic idea of negative stiffness components is based on three-springs device, according to Figure 10. Load bearing capacity is ensured by the vertical spring, zerostiffness is accomplished by inclined springs, which are named as the correcting springs. 


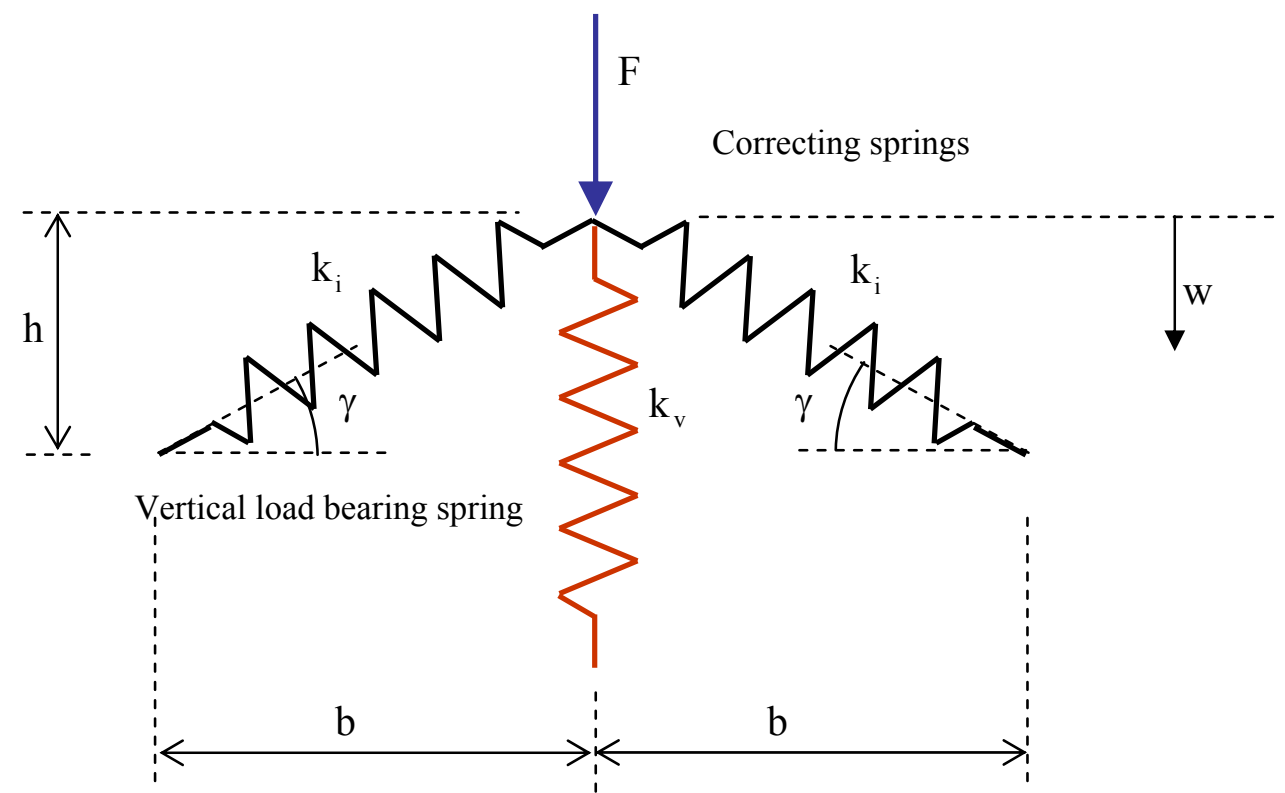

Figure 10: Three-springs device.

Let us assume first static analysis with large displacements of two-springs device formed only by the inclined correcting springs. If external vertical force $\mathrm{F}$ is applied according to Figure 10, then in the deformed position, characterized by the displacement $\mathrm{w}$, the total potential energy of the system is:

$$
\mathrm{U}=2\left(\frac{1}{2} \mathrm{k}_{\mathrm{i}}(\mathrm{L}-\tilde{\mathrm{L}})^{2}\right)-\mathrm{FW},
$$

where $\widetilde{L}=\sqrt{\mathrm{b}^{2}+(\mathrm{h}-\mathrm{w})^{2}}$. From fundamental theorems, at static equilibrium:

$$
\frac{\partial \mathrm{U}}{\partial \mathrm{w}}=0 \Rightarrow \mathrm{F}=-2 \mathrm{k}_{\mathrm{i}}(\mathrm{L}-\tilde{\mathrm{L}}) \frac{\partial \tilde{\mathrm{L}}}{\partial \mathrm{w}}=2 \mathrm{Lk}_{\mathrm{i}} \lambda \sin \gamma\left(1-\frac{1}{\sqrt{\cos ^{2} \gamma+\lambda^{2} \sin ^{2} \gamma}}\right)
$$

where dimensionless parameters are introduced as:

$$
\cos \gamma=\frac{\mathrm{b}}{\mathrm{L}}, \sin \gamma=\frac{\mathrm{h}}{\mathrm{L}}, \lambda=\frac{\mathrm{w}-\mathrm{h}}{\mathrm{h}}, \hat{\mathrm{w}}=\frac{\mathrm{w}}{\mathrm{L}} .
$$

Implementing $\hat{\mathrm{F}}=\frac{\mathrm{F}}{\mathrm{k}_{\mathrm{i}} \mathrm{L}}$ one obtains:

$$
\hat{\mathrm{F}}=2 \lambda \sin \gamma\left(1-\frac{1}{\sqrt{\cos ^{2} \gamma+\lambda^{2} \sin ^{2} \gamma}}\right)
$$


Force-displacement dependence has in the beginning one sine-type wave curve of total length of $2 \mathrm{~h}$ and then it growths up. In Figure 11 a case for $\cos \gamma=0.6$ is shown.

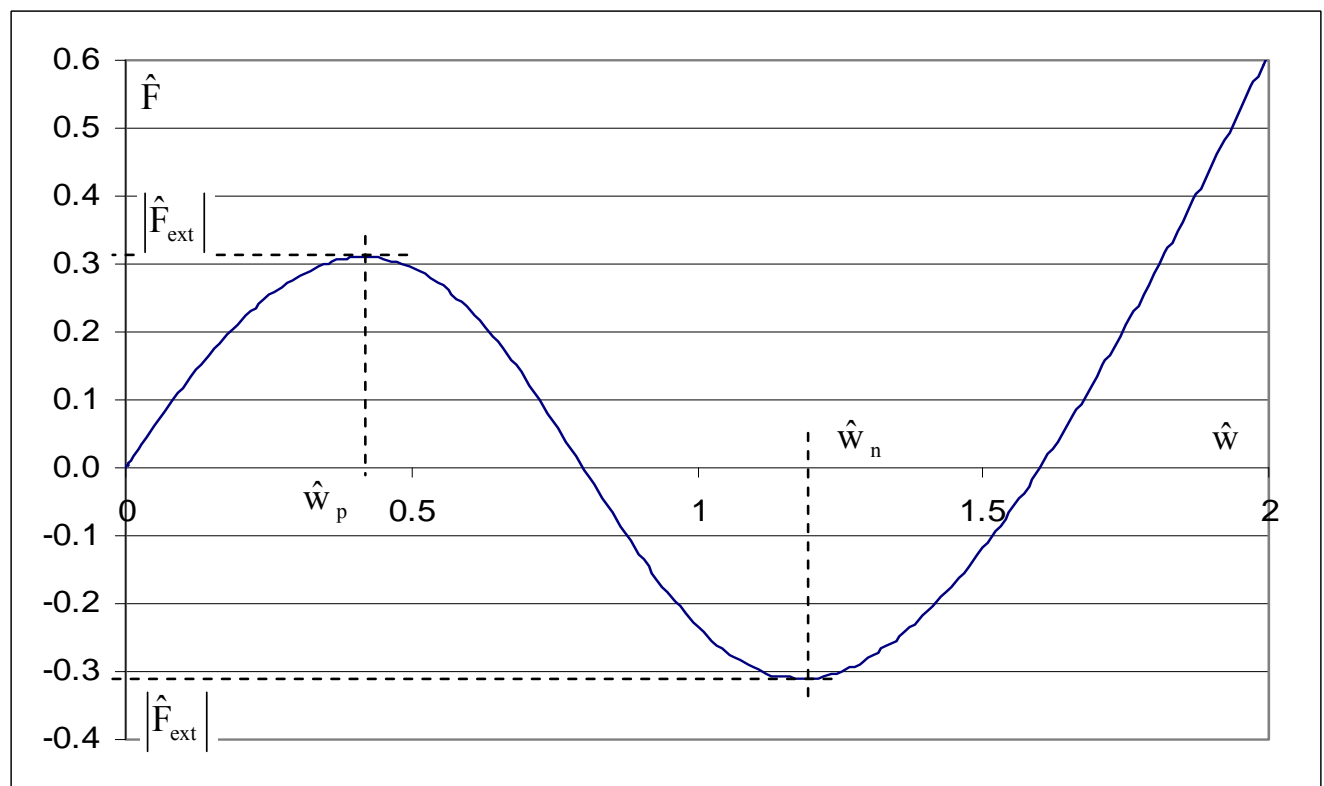

Figure 11: Force-displacement dependence of two-springs system when $\cos \gamma=0.6$.

Local extremes of this curve are at:

$$
\hat{\mathrm{w}}_{\mathrm{p}}=\cos \gamma\left(1-\frac{\cos \gamma}{\sin \gamma} \sqrt{\cos ^{-\frac{2}{3}} \gamma-1}\right) \text { and } \hat{\mathrm{w}}_{\mathrm{n}}=\cos \gamma\left(1+\frac{\cos \gamma}{\sin \gamma} \sqrt{\cos ^{-\frac{2}{3}} \gamma-1}\right)
$$

and the absolute value of the extreme force value is:

$$
\left|\hat{\mathrm{F}}_{\mathrm{ext}}\right|=2\left(1-\cos ^{\frac{2}{3}} \gamma\right)^{3 / 2}
$$

In Figure 12 two-springs system response is plotted for various values of the angle $\gamma$.

In order to ensure the required load bearing capacity (response to static load), it is necessary to introduce the vertical spring of stiffness $\mathrm{k}_{\mathrm{v}}$. Then:

$$
\hat{\mathrm{F}}=\hat{\mathrm{k}} \sin \gamma(\lambda+1)+2 \lambda \sin \gamma\left(1-\frac{1}{\sqrt{\cos ^{2} \gamma+\lambda^{2} \sin ^{2} \gamma}}\right)=\Phi(\hat{\mathrm{k}}, \gamma, \lambda),
$$


as the springs are connected in parallel. In Equation (9) $\hat{\mathrm{k}}=\mathrm{k}_{\mathrm{v}} / \mathrm{k}_{\mathrm{i}}$; in non-linear function $\Phi, \mathrm{k}_{\mathrm{v}}$ and $\gamma$ are parameters, $\lambda$ is a variable.

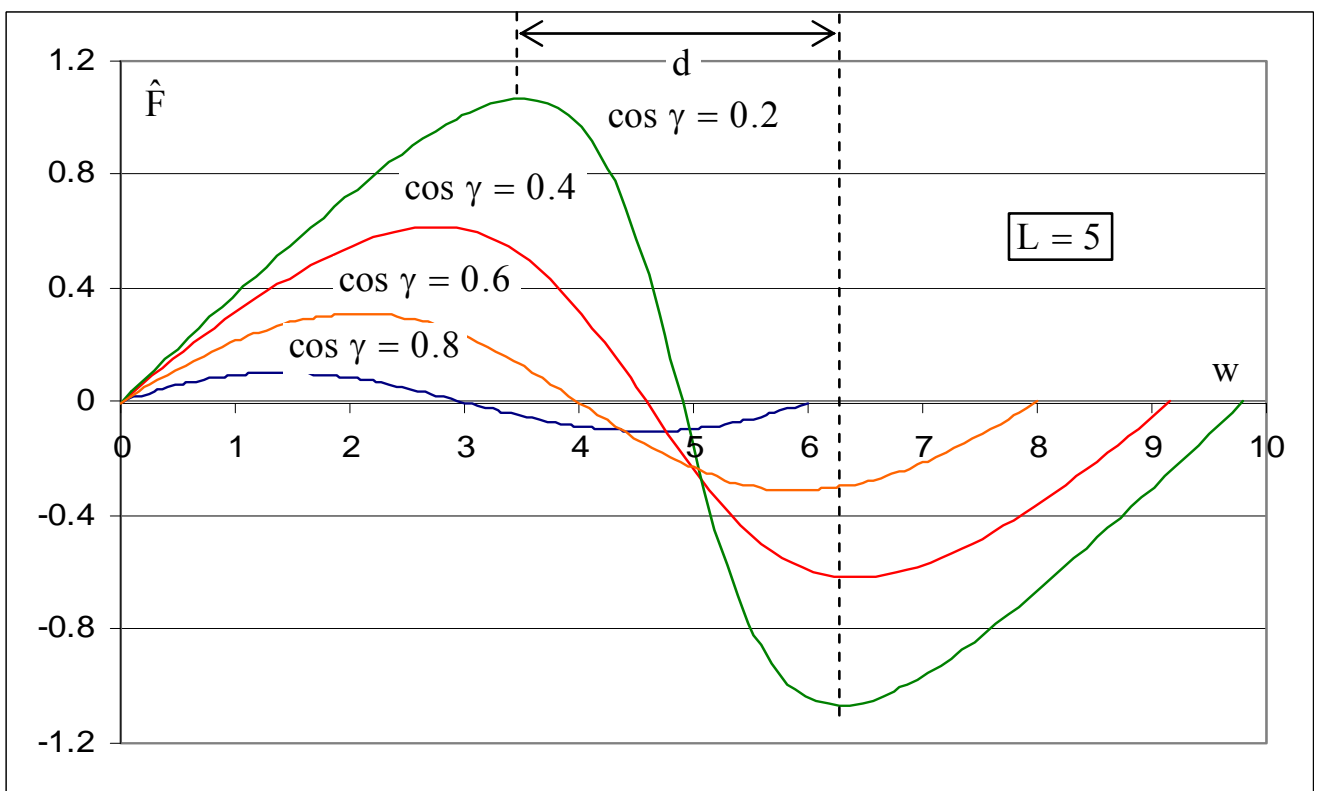

Figure 12: Force-displacement dependence of two-springs system for various values of the angle $\gamma$.

One of the objectives of optimization can be to achieve stable behaviour at the longest plateau. In order to achieve the longest plateau, the relative extremes maximum distance must be ensured. Simple calculation yields that the longest plateau is reached for the lowest angle when the distance is compared to $\mathrm{h}$ and for $\cos \gamma=2 \sqrt{6} / 9 \Rightarrow \gamma=57^{\circ}$ when it is compared to L. Low angle has the disadvantage that the dimensionless force maximum is low (see Figure 12). In order to avoid unstable behaviour, relative stiffness $\mathrm{k}_{\mathrm{i}} / \mathrm{k}_{\mathrm{v}}$ must have the following value:

$$
\frac{\mathrm{k}_{\mathrm{i}}}{\mathrm{k}_{\mathrm{v}}}=\frac{\cos \gamma}{2(1-\cos \gamma)}
$$

which ensures zero value in the middle of the plateau, but increasing forcedisplacement curve. Using the previous results, if for instance $\sin \gamma=0.1$ and $\mathrm{h}=0.01 \mathrm{~m}$, zero-stiffness is reached at the displacement $\mathrm{w}=0.01 \mathrm{~m}$ and thus the plateau force has the value of $0.01 \mathrm{k}_{\mathrm{v}}$. For unit value of $\mathrm{k}_{\mathrm{v}}, \mathrm{k}_{\mathrm{i}}=99$ yields and the corresponding comparison of the two- and the three-springs system forcedisplacement curve is plotted in Figure 13. 


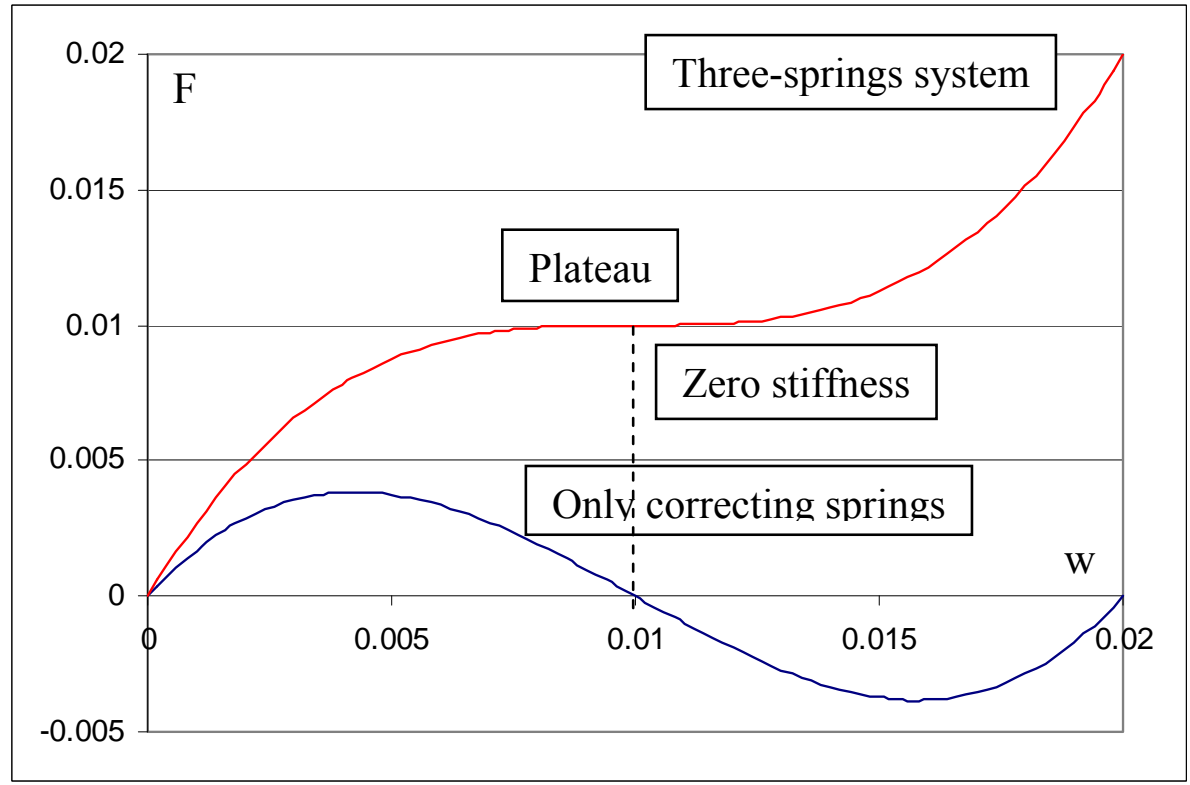

Figure 13: Force-displacement dependence for $\sin \gamma=0.1$ and optimized stiffness ratio according to Equation (10) (blue curve: two-springs; red curve: three-springs system).

It is known, that the red curve in Figure 13 resembles the typical cellular material behaviour. However, in cellular materials plateau is usually caused by irreversible deformation. New hyperelastic microcellular materials following this typical curve are under investigation by research community. These materials, even without any damping introduced, can reduce very efficiently either upward or downward directed accelerations. In order to examine this behaviour, free vibrations of the system must be studied and thus concentrated mass m must be placed on the top of the system. This is in accordance with railway applications, if a continuous material with this behaviour would be used as interface pad, then it would be suddenly displaced by $40 \%$ of the axle load and liberated, originating free vibrations. According to [11], analytical solution of natural free vibrations can be done in the following way. Equation of dynamic equilibrium can be transformed in the system of two equations:

$$
\mathrm{x}_{1}=\lambda \text { and } \mathrm{x}_{2}=\dot{\lambda}
$$

In the undamped system:

$$
\dot{\mathrm{x}}_{1}=\mathrm{x}_{2} \text { and } \dot{\mathrm{x}}_{2}=-\Phi(\hat{\mathrm{k}}, \gamma, \lambda)+\phi
$$

where the dot designates derivative with respect to the dimensionless time $\tau=\mathrm{t} \sqrt{\frac{\mathrm{k}_{\mathrm{i}} \mathrm{L}}{\mathrm{mh}}}$ and $\phi=\frac{\mathrm{F}}{\mathrm{k}_{\mathrm{i}} \mathrm{L}}$ corresponds to the applied dimensionless force. 
Implicit solution curve of Equations (11-12), in terms of $\lambda$ and $\dot{\lambda}$, can be obtained by comparison of energy stage between the initial and current configuration, as described in [11]. Analysis of these curves allows determination of initial conditions, in the way to control the maximum amplitude of the free vibrations. In Figure 14 implicit curves are plotted for various stiffness ratios; $\mathrm{k}_{\mathrm{vo}}$ designates the vertical stiffness obeying Equation (10).

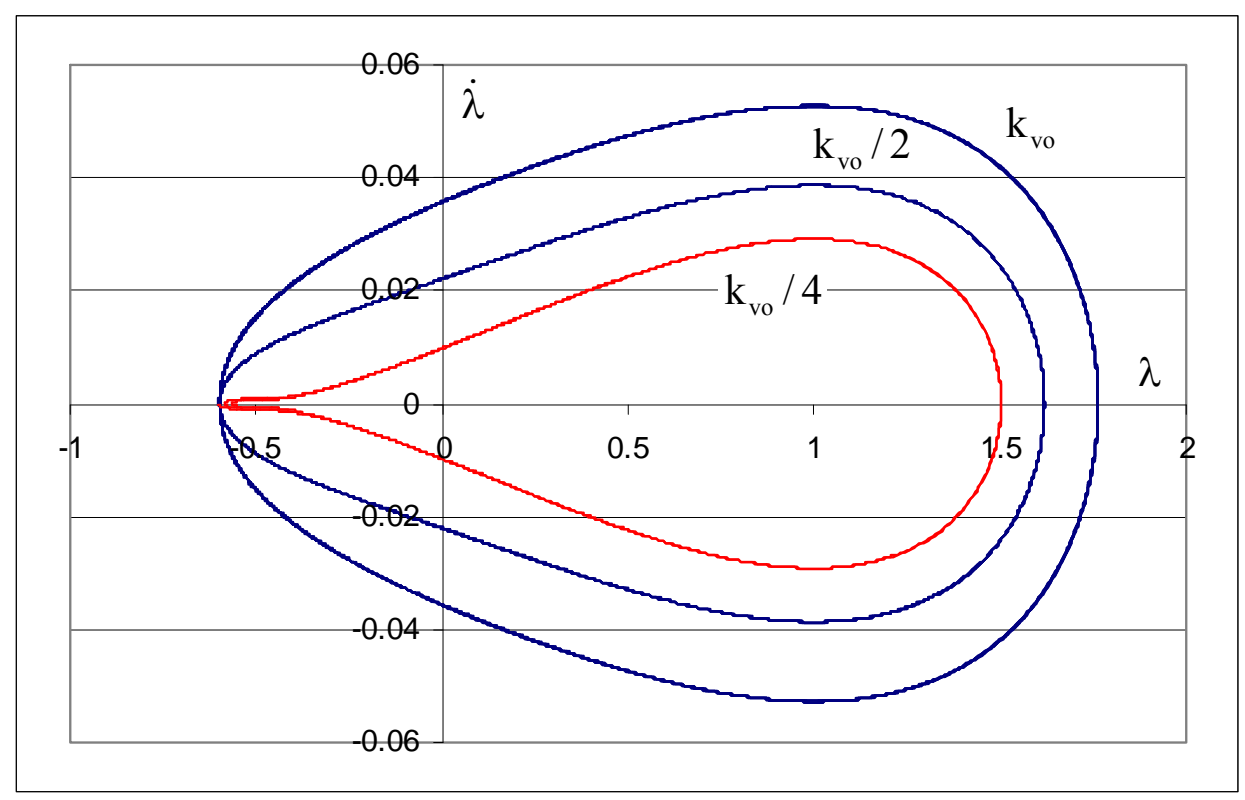

Figure 14: Implicit solution curve of Equations (11-12); vibrations are originated by initial dimensionless displacement of 0.6 directed downward.

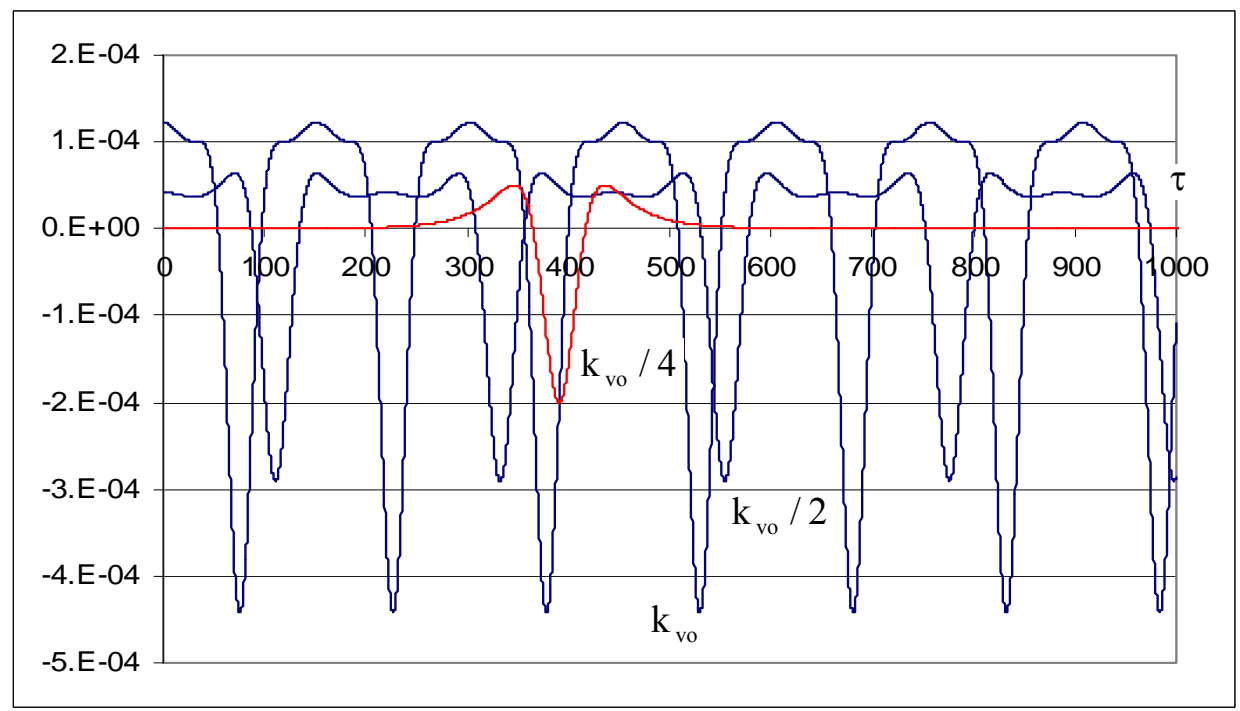

Figure 15: Accelerations of free vibrations originated by dimensionless displacement of 0.6 directed downward, along the dimensionless time. 
Corresponding accelerations evolution over dimensionless time is plotted in Figure 15. A non-typical distribution can be seen. In the case of $\mathrm{k}_{\mathrm{vo}} / 4$ (red curve) quite a long period of time does not suffer almost any acceleration.

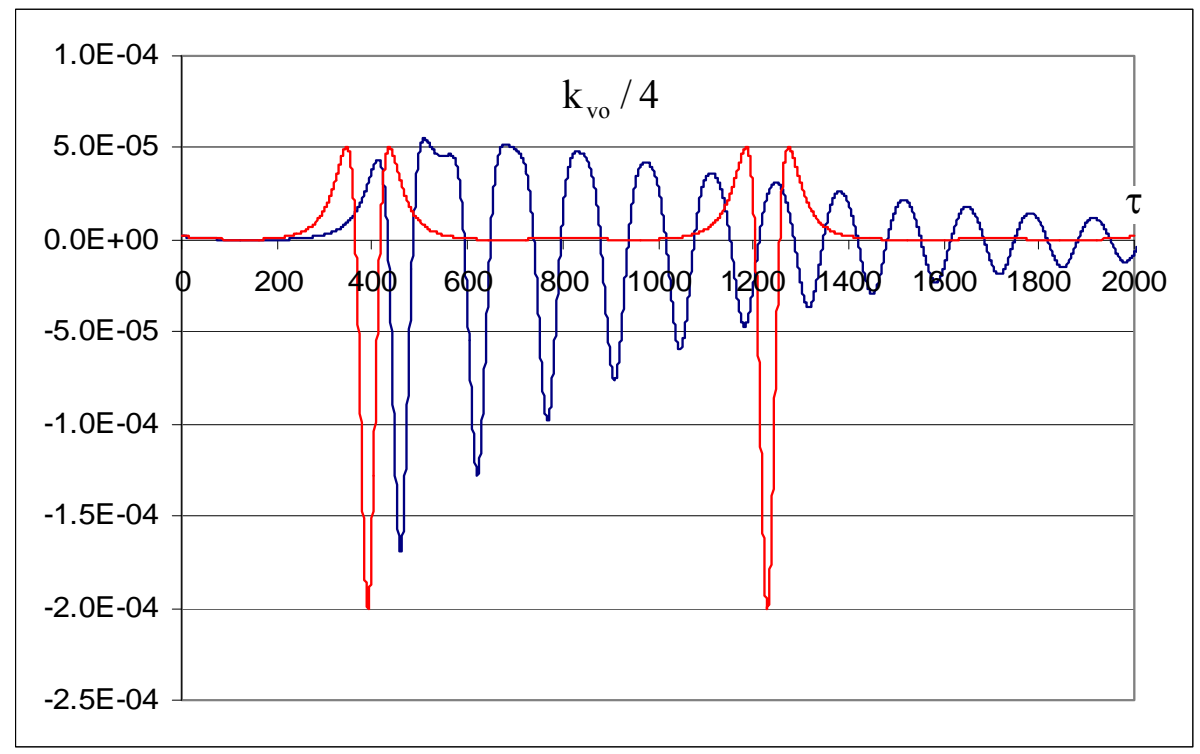

Figure 16: Accelerations of free vibrations originated by dimensionless displacement of 0.6 directed downward, along the dimensionless time (red curve: undamped; blue curve: damped).

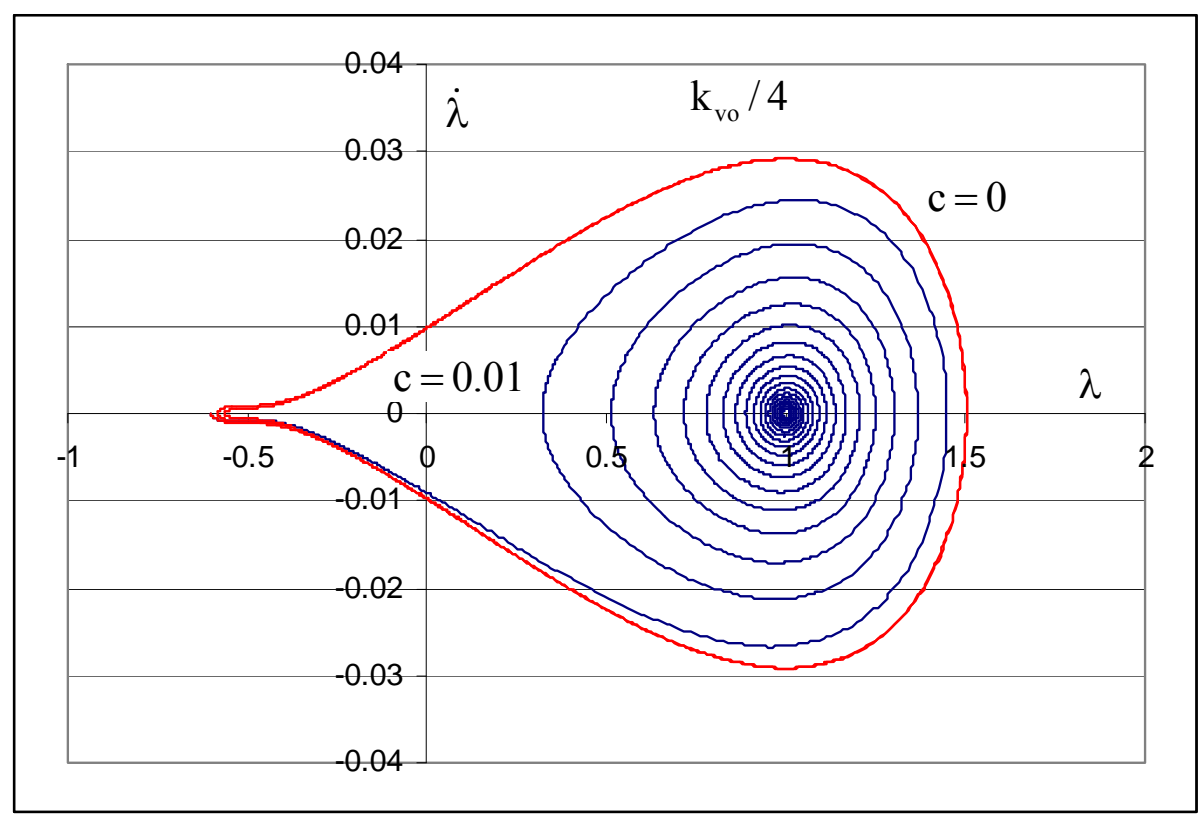

Figure 17: Implicit solution curve of Equations (11-12); vibrations are originated by initial dimensionless displacement of 0.6 directed downward (red curve: undamped; blue curve: damped). 
However, if damping is added ( $\mathrm{c}=0.01$ was used in this example), displacements leave rapidly the plateau region and accelerations resemble back the standard distribution, see Figure 16. Corresponding implicit curve solution is in Figure 17. Damping influence returns back the mechanism to static equilibrium position, as expected.

\subsection{Optimal composites}

Further research is now directed to the most efficient utilization of quasi-zero stiffness components. Composites with negative stiffness inclusions in a viscoelastic matrix are shown to have higher stiffness and mechanical damping and than that of either constituent. Best performance can be achieved if they are arranged as a Reuss laminate [9-10]. Classical Reuss bound can be rewritten by dynamic correspondence principle of the theory of linear viscoelasticity [12], for instance for Young's modulus it holds:

$$
\frac{1}{\mathrm{E}_{\mathrm{c}}^{*}}=\frac{\mathrm{v}_{1}}{\mathrm{E}_{1}^{*}}+\frac{\mathrm{v}_{2}}{\mathrm{E}_{2}^{*}}
$$

where $\mathrm{v}_{1}, \mathrm{v}_{2}$ are volume fractions of the constituents, $\mathrm{E}_{\mathrm{c}}^{*}, \mathrm{E}_{1}^{*}, \mathrm{E}_{2}^{*}$ stand for complex Young's moduli of the resulting composite and its constituents. For effective isotropy Reuss bound can be improved by Hashin-Shtrikman bound, however in this case Reuss bound is lower and thus better for our purpose. Hierarchical laminates can provide the solution.

\section{Analysis in Transversal cut}

As already mentioned, this analysis can only be used for qualitative comparison of different approaches in soil damping modelling. It is known that the adoption of inappropriate damping coefficients can drastically distort the output. This is shown in Figure 18, where surface accelerations are shown at selected times for loading curve corresponding to Thalys High-Speed Train [5-6].

It was also already mentioned, that in the soil numerical modelling, usually frequency dependent Rayleigh damping is implemented, but experience shows that energy is dissipated in soils by internal friction, which does not depend on frequency. In addition, Rayleigh damping requires evaluation of damping constants $\alpha$ and $\beta$ according to the given damping ratio, and this evaluation uses directly values of first two natural frequencies. It is simple to show, that such definition is ambiguous, as frequencies and mode shape order are strongly influenced by the model size and shape. This fact is demonstrated in Figures 19-20, where first and second natural frequencies are plotted with respect to the aspect ratio (length/depth) of the model. It was also verified that typical mode shapes are not ordered in the same way and that the frequencies tend down with the increasing model size.

In conclusion, soils damping should be modelled only as a hysteretic loss. ANSYS allows several approaches to these models, their comparison is currently 
under investigation. Satisfactory results were already obtained with hysteretic energy loss as it is available for shape memory alloys. Although, the model is developed for completely different usage, in regions subjected to compression only, adequacy is more or less acceptable.

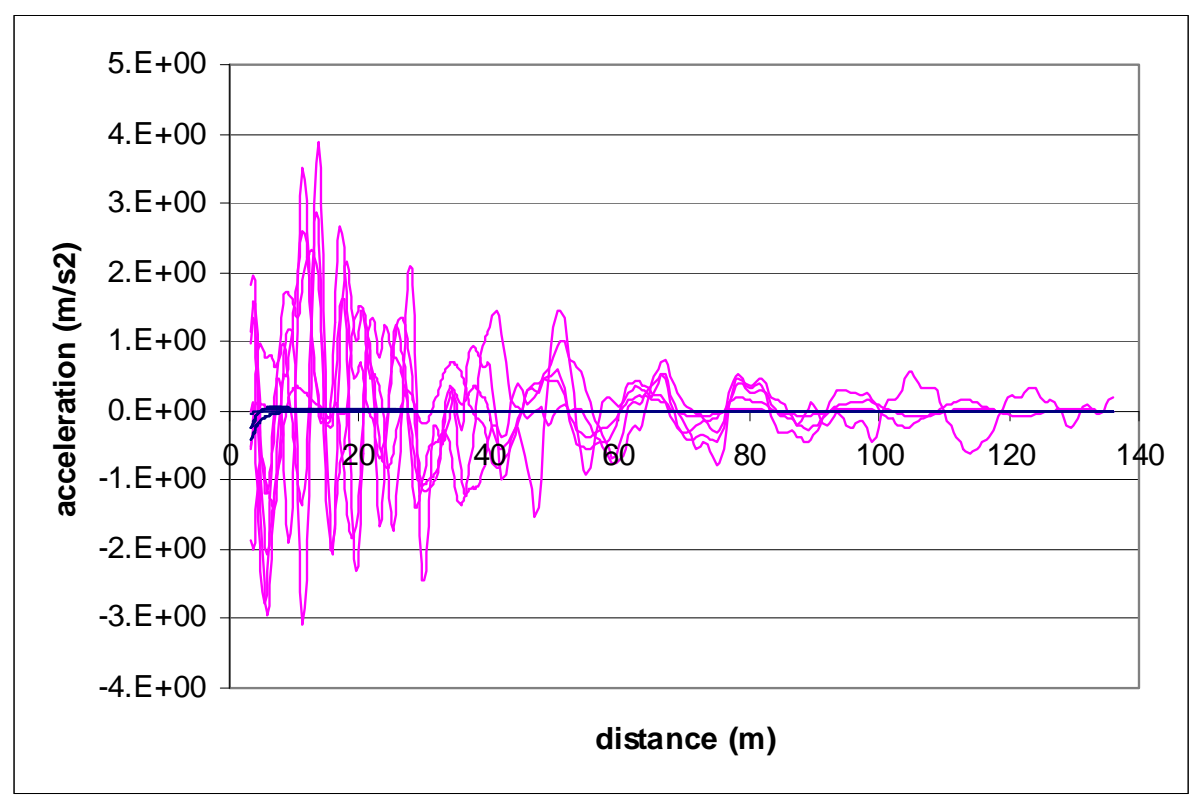

Figure 18: Vertical surface accelerations at selected times corresponding to passage of Thalys High-Speed Train obtained by 2D model (violet curves: no substrates damping, blue curves: $\beta=0.03$ in substrates).

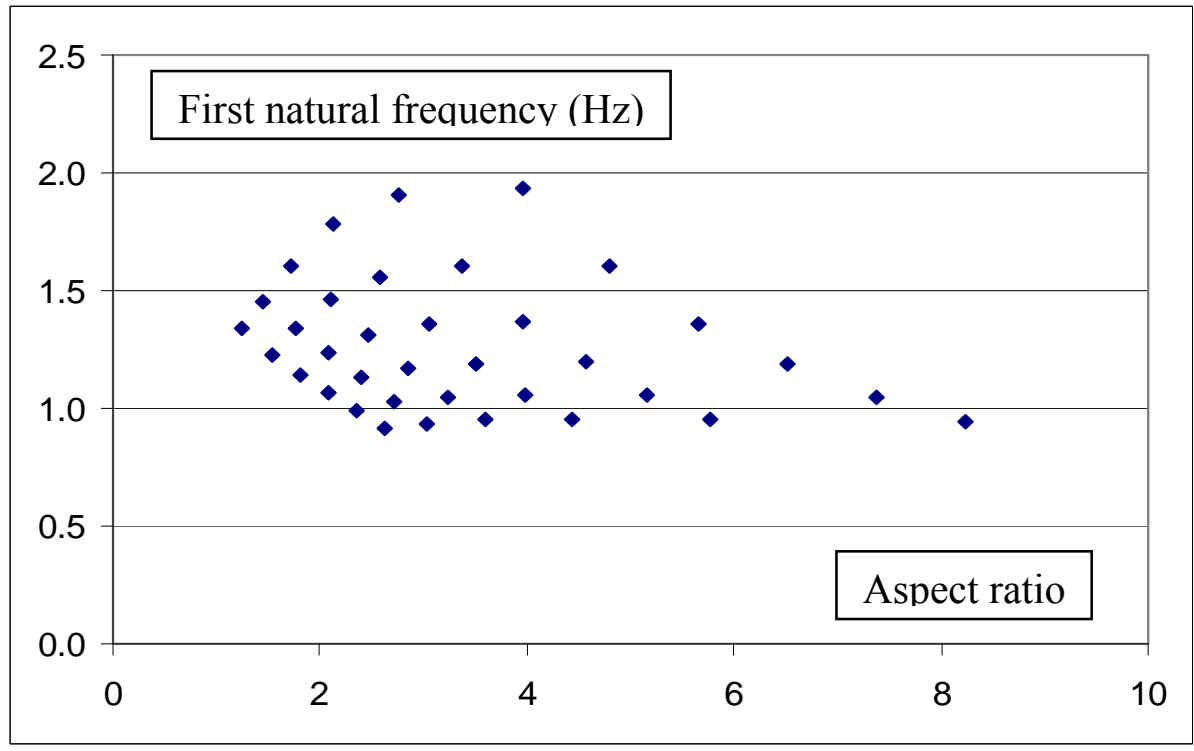

Figure 19: First natural frequency $(\mathrm{Hz})$ with respect to aspect ratio of the model. 


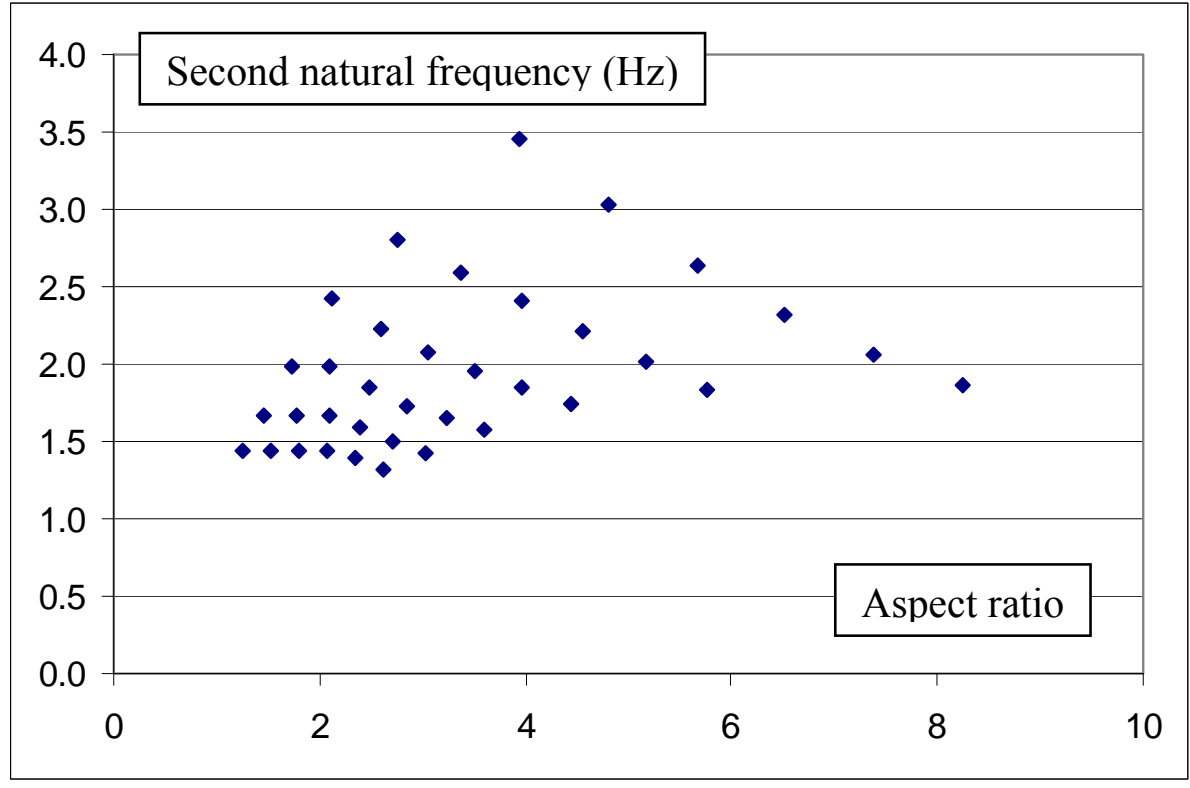

Figure 20: Second natural frequency $(\mathrm{Hz})$ with respect to aspect ratio of the model.

\section{Conclusion}

In this paper influence of damping on vibration induced by high-speed trains is studied. It is mentioned, that there are basically two levels of damping, one is inherent to the interface material implemented in the rail-sleeper fixing system, the other one is a consequence of hysteretic soil properties and must be modelled correctly to obtain reliable results. Full understanding and correct modelling of the latter feature is inevitable for soils improvement treatment suggestion. Interface damping can be controlled directly, and might be improved by introduction of new and more efficient materials. It is concluded that interface damping can be studied and analysed in longitudinal cut analysis and that qualitative comparison of soils damping modelling can be performed in transversal cut analysis. Preliminary results on interface damping are obtained exploiting novel materials and composites. Regarding soils damping modelling, it is concluded that the most common implementation as Rayleigh damping does not seem to be the correct approach for two reasons: (i) calculation of damping constants $\alpha$ and $\beta$ is ambiguous; (ii) experience shows that energy is dissipated in soils by internal friction in hysteretic loops with no dependence on frequency. Preliminary results implementing hysteretic energy loss are obtained exploiting software ANSYS.

\section{References}

[1] A.M. Kaynia, C. Madshus and P. Zackrisson, "Ground Vibration from HighSpeed Trains: Prediction and Countermeasure", Journal of Geotechnical and Geoenvironmental Engineering, 126, 531-537, 2000. 
[2] D. Park and Y.M.A. Hashash, "Soil damping formulation in nonlinear time domain site response analysis", Journal of Earthquake Engineering, 8(2), 249-274, 2004.

[3] V.L. Markine, A.P. de Man, S. Jovanovic and C. Esveld, "Multicriteria Optimisation of Railway Track for High-Speed Lines", 2nd ASMO UK / ISSMO Conference on Engineering Design and Optimization, Swansea Wales, UK, 2000.

[4] Release 10.0 Documentation for ANSYS, Swanson Analysis Systems IP, Inc., 2006.

[5] G. Degrande and L. Schillemans, "Free Field Vibrations during the Passage of a Thalys High-Speed Train at Variable Speed", Journal of Sound and Vibration 247(1), 131-144, 2001.

[6] G. Degrande, "Free field vibrations measurements during the passage of a Thalys high speed train", Internal report BWM-2000-06, Katholiere Universiteit, 2000.

[7] A. Lundquist and T. Dahlberg, "Dynamic train/track interaction including model for track settlement evolvement", Vehicle System Dynamics, 41(supplement), 667-676, 2004.

[8] L. Frýba, "Vibration of solids and structures under moving loads", $3^{\text {rd }}$ Edition. Thomas Telford, 1999.

[9] R.S. Lakes, "Extreme Damping in Composite Materials with a Negative Stiffness Phase", Physical Review Letters, 86(13), 2897-2900, 2001.

[10] R.S. Lakes, "High Damping Composite Materials: Effect of Structural Hierarchy", Journal of Composite Materials, 36(3), 287-297, 2002.

[11] M. Jirásek, Simple non-linear system simulation, Internal Report, Czech Technical University in Prague, 1988, (in Czech).

[12] Z. Hashin, "Viscoelastic behavior of heterogeneous media", Journal of Applied Mechanics, Trans. ASME, 32E, 630-636, 1965. 